\title{
River Water Assessment and Prediction Modelling
}

\author{
Visnu Darshini, Manu Satwik, Prudhvi, Harshith
}

\begin{abstract}
This is a wireless based water quality checking system. It is a WSN which includes a raspberry pie for processing the system and various sensors like $\mathrm{pH}$, turbidity, temperature, conductivity. Internet of things acts as a query to response service and remote communication technology in sending and receiving the data. Using $k$-means clustering a machine learning algorithm which helps in measuring large amounts of data and comparing the data with the standard values. Any fluctuations in the data with the recorded values will notify the system. The information is monitored constantly and consigned to a cloud. Therefore this system immensely helps in assessing the quality of contaminated water with prediction modelling. 1
\end{abstract}

Keywords: Internet of things, k-means clustering, assessing, prediction modelling, wireless network.

\section{INTRODUCTION}

Rivers, swamps and lakes are very important bodies of water for all the living beings on the earth. But nowadays these water bodies and its resources are altered very crudely by many elements such as domestic waste, industrial waste, sewage etc. Due to which the water is polluted and adversely affected. Elimination of pollution altogether is unfathomable, but limiting its affects are merely possible in acting.The uncontrolled urbanisation and industrialisation are olluting the meagre amount of fresh water available in rivers. Many initiatives are been applied all over the globe to aid the marine environments. They are not specifically into river water quality monitoring but many similar concepts are involved. Traditional methodologies have much complicated methods and many disadvantages such as low precision, high cost, and long waiting time for the results. Water quality monitoring has gained this recognition in the last decade. Numerous works are ongoing in this concept with their primitive goal on eradication of water pollution and various aspects of it. This paperdepicts the design of wireless sensor networks with IOT and k-means clustering algorithm to analyse and predict the pollutants in river water.

\section{EXISTING SYSTEM}

- The existing system uses sensors tocollect data.

- Pollutant values are only stored in the cloud for the analysis and the those systems are not deliberately accurate in measuring.

Revised Manuscript Received on April 17, 2020.

* Correspondence Author

Visnu Darshini*, Department of CSE, SRM University, Chennai, India. Manu Satwik, Department of CSE, SRM University, Chennai, India.

Prudhvi, Department of CSE, SRM University, Chennai, India.

Harshith Suresh, Department of CSE, SRM University, Chennai, India.

(C) The Authors. Published by Blue Eyes Intelligence Engineering and Sciences Publication (BEIESP). This is an open access article under the CC BY-NC-ND license (http://creativecommons.org/licenses/by-nc-nd/4.0/)
The present system deliberately focuses on finding the pollutant levels in the contaminated water.

- Furthermore these systems are based on conserving coral reefs, salinity and nutrients of the reefs.

- The old systems collects the water samples from different locations test them in laboratories to obtain the results.

- The older traditional methods only store the data whereas our model uses machine learning algorithms to predict and compare the results.

\section{PROPOSED SYSTEM}

- The main motto of the project is creating a uninterrupted checking of the river water quality.

- This system audits the rivers and monitor the values accurately and are available in a portal and public domain.

- We can watch the live condition of the river through satellite remote sensing.

- K-means clustering algorithm can handle cluster amount of data.

- $\quad$ This system is out built with very low cost and high efficiency by using raspberry pie as control processor.

- This whole system can be monitored by any government body and any live disposal of waste can be intimated.

- Working of the system is level-headed frequently which makes a continuous monitoring all time.

\section{LITERATURE SURVEY}

In 2019 Mohammad Salah Chowdury proposed Iot based water quality monitoring in this paper Analysis of polluted water using belief rule based system and deep learning neural networks for an automated sms alert. [1]

In 2018 Dilshad Ahmed proposed Iot based smart river monitoring system which briefs us on monitoring the water and pollutant value results are consigned to a database using tcp protocol and sends a Api push notification to the authorities. [2]

In 2018 A.N.Prasad proposed Smart river water quality tracking system which is a frequent data collecting network by using iot and sensing technology which is a graphical representation shows the behavioural data of the water. [3] In 2014 K. Anderson "Smart Risk surveiling Systems using b-r-b, and WSN Technologies", is 4th International Conference on Wireless Communication, Vehicular Technology and Information, VITAE 2014 : Co-located with Global Wireless Summit. [4]

In 2018 Gayathri Surendran and Ganesh Udupa, G.J. Nair Design of modelling a cable suspended sonde for water quality recording Published in International Conference on Computing, Instrumentation

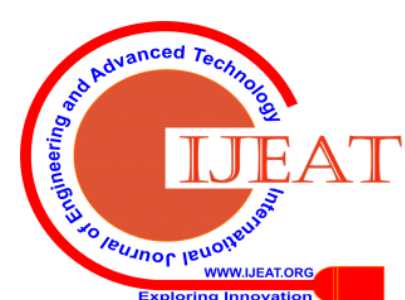




\section{River Water Assessment and Prediction Modelling}

and Control processes. [5]

In 2018 S. Fang, L. Da Xu, Y. Zhu, J. Ahati, and Z. Liu "An integrated system for regional environmental finding and managing based technology .," IEEE Transactions on Industrial Informatics vol. 10, pp. 1596-1605., [6]

\section{SYSTEM ARCHITECTURE}

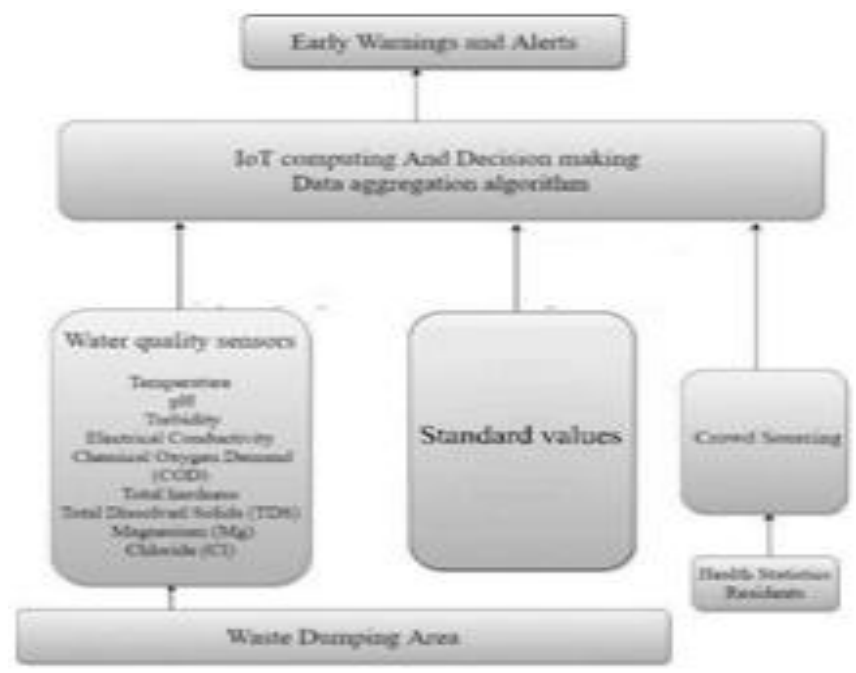

Fig.no.1 System architecture

From the fig .no. 1 the implementing system consists of a classification algorithm which used as a profront processing for entire system and mainly used to determination.

\section{METHODOLOGY}

1 Raspberry pie

2 WSN

3 Software

4 K-means clustering

\section{Raspberry Pie}

The Raspberry Pie is a low priced board computer docks with USB, Ethernet, Micro SD card slot, audio, HDMI and power provision. This is the most crucial unit in the system. It intakes sensor data as input and gives out the valve on LCD.

The water standard is determined monitored and calculations are carried out by raspberry pie.

\section{Wireless Sensor Network (WSN)}

Utilizing a system of sensors which is remote to transmit the information and the parameters they have considered for testing the water quality are $\mathrm{pH}$, turbidity, dissolved oxygen and temperature, phosphate, conductivity and water level which are actualizing the water structure and pollutants. Normally a remote sensor system contains the countless hubs. The sensors can part among themselves using radio signs. A remote sensor is outfitted with detecting and the registering gadgets, radio handsets . The individual hubs in a remote organized are intrinsically asset compelled and they have handled speed,stock limit, and transfer speed.

\section{Software}

Thing Speak is an IoT platform which lets you collect and store data in the cloud and develop applications. The Thing Speak platform provides applications which help you analyze and visualize your data in a system, and acts on the data. raspbian is a Debian PC working framework for Raspberry Pi. There are a few variants of Raspbian including Buster and Stretch. Since 2015 it has been authoritatively given by the Raspberry Pi Establishment as the essential framework group of Raspberry Pi single-board PCs

\section{K-means Clustering}

This is a clustering algorithm which helps is analysing the enormous amount of data. It operates better on the clusters distributed rather which are accentral.

It selects its cluster heads based on the two factors:-

1. Euclidian Distances

2. Residual energies of nodes

This algorithm works on distributed nodes as if the central node is failed the whole system is failed whereas the distributed nodes work if one is failed.

Table.no.1 Comparison of Values

\begin{tabular}{|c|c|c|}
\hline Characteristics & River Water & Wedl \\
\hline Turbidity (NTU) & 5.4 & 32 \\
\hline $\mathrm{pH}$ & 8.03 & 7.05 \\
\hline $\begin{array}{l}\text { Electrical } \\
\text { Conductivity }\end{array}$ & 1358 & 289.0 \\
\hline Temperature & 29 & 29 \\
\hline Acidity & 9 & 30.0 \\
\hline Alkalinity & 70 & 82 \\
\hline $\begin{array}{l}\text { Total Dissolved } \\
\text { Solids (TDS) }\end{array}$ & 674 & 149 \\
\hline $\begin{array}{l}\text { Total hardness } \\
\text { (CaCO3) }\end{array}$ & 184 & 112 \\
\hline Cakium (Ca) & 64.1 & 43.29 \\
\hline Magnesium (Mg) & 5.83 & 0.97 \\
\hline Chloride (CI) & 347.41 & 36.87 \\
\hline Fluoride (F) & Nil & Nil \\
\hline Iron (Fe) & 0.7 & 0.3 \\
\hline Nitrate (NO3) & 10 & 30.0 \\
\hline $\begin{array}{l}\text { Chemical Oxygen } \\
\text { Demand(COD) }\end{array}$ & Nil & Nil \\
\hline Phosphate (PO4) & Nil & Nil \\
\hline Ammonia & 1.0 & Nil \\
\hline
\end{tabular}

Published By:

Blue Eyes Intelligence Engineering 


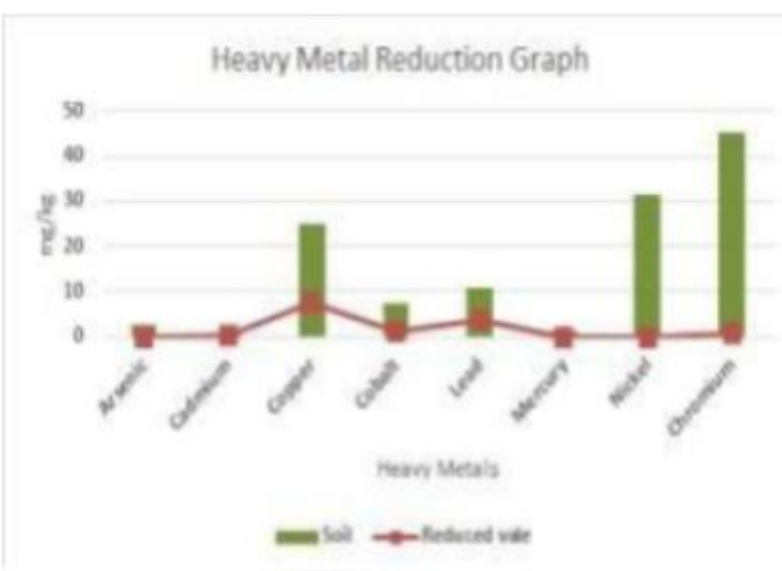

Fig.no.2 Graphical Result

The above figure and graph represents the simulation result of the pollutants and characteristics present in the river water. In this remediation process we can find the hazardous heavy metallic ions and theirthereshold values. The acquired values are equal or less to the standard values which is referred as good unless it is referred as bad. The graphical representation is the perfect understanding for the process. Here the $\mathrm{K}$ - means clustering algorithm compares all the data in the cluster to give a real time understanding of the river water. The quality parameters are given in the clusters as inputs where it runs a combination of data to produce a perfect result.

\section{CONCLUSION \& DISCUSSION}

In this system we've given a machine learning pipeline for the assessing the grade of the river water. The system immensely focuses on the monitoring of river water quality. This system is appeared to be a better blend on persistence and speed. Using the WSN and clustering algorithm concepts which brings the life into this project. And all the data collected through sensors are legit and rectified. These values are compared to the fresh water in the wells and canals to bring subtle values of the pollutants and characteristics present in the water. The results obtained are gone through statistics to provide a better understanding of the concept.In this work we evaluated the results we gained to those standard values for a definitive results and the frame work this system produced is always represented graphically for a better understanding.

\section{REFERENCES}

1 Taufik Ibnu Salim, Hilman S. Alam and Rian P. Pratama, "Portable and online water quality monitoring system using wireless sensor network", 2nd International conference IEEE ICACOMIT 2017, Accession number: 17487078, January 2018.

2 N.Suresh , E.Balaji ,K.JeffryAnto and J.Jenith "Raspberry pi based fluid stream observing and control" Sathyabama College, Tamil Nadu, India, Volume: Issue: 07 Jul-2014.

3 M.S. Hossain, PO., Zander, S. Kamal, and L. Chowdhury, "Conviction Rule Based Master Frameworks to Assess EGovernment", Master Frameworks, The Diary of Information Designing, Vol. 32, No.5, 2015, Jhon Wiley and ChildrenLtd.

4 P Gopi Krishna el al "Development of Real Time environment monitoring systems using with MSP430" in International Journal of Engineering \& Technology, 7 (2.8) (2018) 72-76.

5 Junsheng Li, Bing Zhang, Xia Zhang, Lianru GaoPreliminary study on the potential of short-wave infrared remote sensing data on inland water quality monitoring.
6 S. Thombre, R. U. Islam, K. Andersson, andM.S. Hossain, "Execution Examination of an IP based Convention Stack for WSNs", in Procedures of the 2016 IEEE Gathering on PC Interchanges Workshops (INFOCOM WKSHPS), 2016, pp. 691-696.

7 Ash, Peter, et al. "Rehabilitating former landfill sites: A case study in habitat restoration." Global Humanitarian Technology Conference (GHTC), 2013 IEEE. IEEE, 2013

8 N. Vijayakumar and R. Ramya, "The real time monitoring of water quality in IoT environment," in 2015 International Conference on Innovations in Information, Embedded and Communication Systems (ICIIECS), 2015, pp. 1-5.

9 Cho Zin Myint, Lenin Gopal, Yan Lin Aung WSN-based reconfigurable water quality monitoring system in IOT environment Published in 2017 IEEE/ACIS 16th International Conference on Computer and Information Science (ICIS).

10 Arjun K, Latha C A, and Prithviraj, Detection of Water Level, Quality and Leakage using Raspberry Pi with Internet of Things, International Research Journal of Engineering and Technology (IRJET), Volume 04 Issue 06, June 2017, pp 2875-2880..

\section{AUTHORS PROFILE}

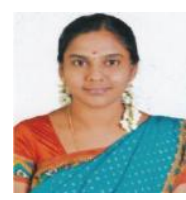

Visnu Darshini, Assistant professor (senior grade), Department of Computer Science and Engineering, SRM Institute of Science and Technology, Chennai.

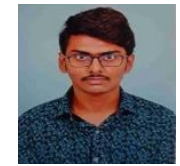

Manu Satwik, Btech Computer Science and Engineering, SRM Institute of Science and Technology, Chennai.

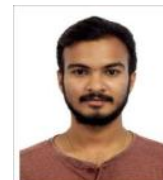

Prudhvi, Btech Computer Science and Engineering, SRM Institute of Science and Technology, Chennai.

Harshith, Btech Computer Science and Engineering, SRM Institute of Science and Technology, Chennai.

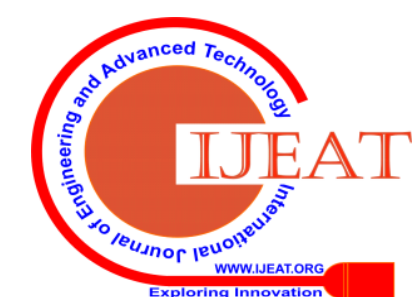

